\title{
Study on the influence of radius of curvature on flow resistance in spiral pipe
}

\author{
Wenqiang $\mathrm{Li}^{1}$, Hui $\mathrm{Qi}^{1}$, Yongfeng Yang ${ }^{1}$, Guojun Zhao ${ }^{1}$, Rong Liu ${ }^{2, *}$, and Haonan Wang ${ }^{2}$ \\ ${ }^{1}$ Power China Road Bridge Group Co, Haidian District, Beijing, 10089, China \\ ${ }^{2}$ State Key Laboratory of Coal Mine Disaster Dynamics and Controls, Chongqing University, Chongqing, 400030, China
}

\begin{abstract}
With the continuous development of west of China, a new kind of tunnel, namely spiral tunnel, has appeared in the expressway. Due to the special linear pattern, the resistance of airflow in spiral tunnel has been found to change, but there are few relevant researches at present. Therefore, numerical calculation method is used to study the variation of flow resistance in spiral pipe with different curvature. The results show that when the fluid flows in the spiral pipe, the wind speed is not uniformly distributed. The highest speed is not in the center of the pipe, but on the outside of the pipe, and the offset distance decreases with the increase of the radius of curvature. In addition, the change of flow resistance in spiral pipe is studied, and it is found that the change rate of flow resistance decreases with the increase of curvature radius. It shows that the radius of curvature is negatively correlated with the flow resistance.
\end{abstract}

\section{Introduction}

When the highway is built in two places with a large difference in height, the spiral tunnel will be built to take the driving safety into consideration. At present, spiral tunnels have appeared in western China. Table 1 lists the spiral tunnels in China. A lot of pollutants will be generated during the construction of the tunnel. However, the spiral tunnel is different from the existing straight tunnel. The special line shape may change the flow resistance of the wind flow in the tunnel. Before the construction of the tunnel, the fan must be selected. The fan selection needs to calculate the maximum air demand and maximum ventilation resistance of the tunnel. The reliability of ventilation system directly affects the safety of tunnel construction and the physical and mental health of workers. The calculated ventilation resistance is lower than the actual ventilation resistance, resulting in the inability of fresh air to enter the tunnel construction area. The calculated ventilation resistance is higher than the actual ventilation resistance, and the ventilation system energy consumption is too high. However, there are few studies on the influence of spiral pipes on resistance.

Ventilation system is the basic guarantee of coal mine safety in the production process, so it is paid much attention in the production process. Ventilation resistance test and distribution analysis will be carried out regularly. ${ }^{[1-4]} \mathrm{Shu} \mathrm{Li}$ and Xuefeng $\mathrm{Liu}^{[5]}$ studied the factors affecting stroke obstruction of urban pipe corridor by means of physical model. According to the method of computational fluid dynamics, Isidro Diego ${ }^{[6]}$ had calculated 138 models with different section dimensions, wind speed and wall surface characteristics, studied the airflow resistance in various situations. Jin Wenliang et al. conducted resistance system tests on zhongnanshan tunnel, Jinping tunnel, Beibei tunnel, and Zhongliangshan tunnel in Qinling Mountains, China. ${ }^{[7-11]}$ As mentioned above, although a lot of literatures have studied the along resistance, few have studied the relationship between the along resistance and the

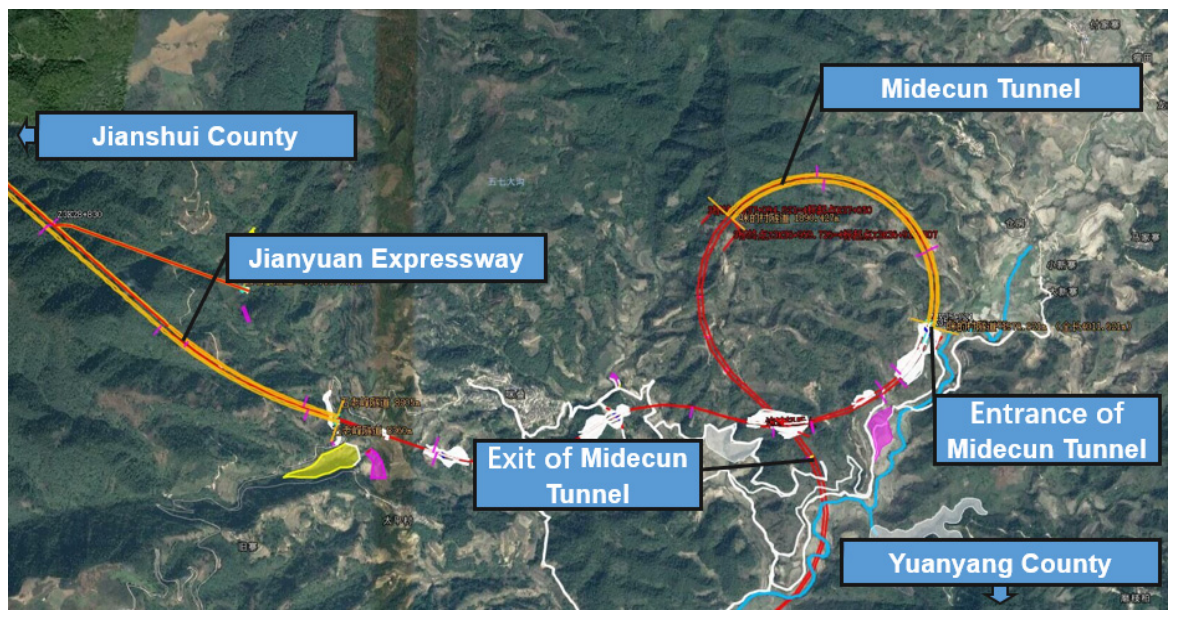

Fig.1. Tunnel location map

* Corresponding author: cqu_liurong@cqu.edu.cn 
radius of the spiral tunnel.

The purpose of this paper is to obtain the variation of ventilation flow resistance in tunnels with different radius of curvature by numerical calculation. The wind flow in the tunnel is the pipe flow in the final analysis. Therefore, this study is not limited to the study of the flow resistance changes in the spiral tunnel, but also to the study of the resistance of the wind flow in the spiral pipe under different curvature radii.

Table 1. The spiral tunnel in China.

\begin{tabular}{|c|c|c|c|}
\hline $\begin{array}{l}\text { Tunnel } \\
\text { name }\end{array}$ & length/m & $\begin{array}{l}\text { radius of } \\
\text { curvature/m }\end{array}$ & expressway \\
\hline $\begin{array}{l}\text { Changhe } \\
\text { lu tunnel }\end{array}$ & $\begin{array}{l}\text { left: } 415 \\
\text { right: } \\
475\end{array}$ & 100 & Changhe road \\
\hline $\begin{array}{l}\text { Ganhaizi } \\
\text { tunnel }\end{array}$ & $\begin{array}{l}\text { left: } \\
1713 \\
\\
\text { right: } \\
1798\end{array}$ & 600 & $\begin{array}{c}\text { Yaxi } \\
\text { expressway }\end{array}$ \\
\hline $\begin{array}{l}\text { Tiezhaiz } \\
\text { i tunnel }\end{array}$ & $\begin{array}{l}\text { left: } \\
2792 \\
\text { right: } \\
2940\end{array}$ & 600 & $\begin{array}{c}\text { Yaxi } \\
\text { expressway }\end{array}$ \\
\hline $\begin{array}{l}\text { Wolong } \\
\text { gou } \\
\text { tunnel }\end{array}$ & $\begin{array}{l}\text { left: } \\
2626 \\
\\
\text { right: } \\
2554\end{array}$ & 700 & $\begin{array}{c}\text { Daxun } \\
\text { expressway }\end{array}$ \\
\hline $\begin{array}{c}\text { Jinjiazhu } \\
\text { ng } \\
\text { tunnel }\end{array}$ & $\begin{array}{l}\text { left: } \\
4228 \\
\text { right: } \\
4104\end{array}$ & 860 & $\begin{array}{l}\text { Yancong } \\
\text { expressway }\end{array}$ \\
\hline
\end{tabular}

\section{Numerical model and calculation}

\subsection{Calculation method of pipe resistance.}

In the process of viscous fluid movement, energy loss is inevitable. In the Bernoulli equation of total flow, the mechanical energy loss of unit weight fluid is expressed as the head loss. Viscosity is the root cause of head loss, ideal fluid flow, because of no viscosity, so no head loss. According to the different flow boundary conditions and mechanism of the head loss, the head loss can be divided into the on-way resistance and the local resistance. The experiment shows that the water head loss $h_{f}$ along the pipe and non-pipe flow is directly proportional to the flow length $l$ and inversely proportional to the pipe diameter $d$. The calculation formula is as follows:

$$
h_{f}=\lambda \frac{l}{d} \frac{v^{2}}{2 g}
$$

And local head loss calculation formula:

$$
h_{f}=\zeta \frac{v^{2}}{2 g}
$$

\subsection{Introduction of Midecun Tunnel}

Spiral tunnel site ventilation resistance test is selected in Yunnan Province (a) yuan expressway mi village tunnel entrance right hole. The left line (Z3K35+076 Z3K38+906) long $3830 \mathrm{~m}$, the right line $(\mathrm{K} 35+110$ $\mathrm{K} 39+080$ ) long $3970 \mathrm{~m}$, the tunnel is a spiral tunnel, the height difference between the entrance and exit is about $80 \mathrm{~m}$, the longitudinal slope of the tunnel is $-2.08 \%$, $-2.05 \%$ (one-way slope) tunnel entrance axis direction $147^{\circ}$, the maximum buried depth of $366 \mathrm{~m}$, is a deep buried long tunnel. The location area of Midecun tunnel is in Hani-Yi Autonomous Prefecture of Honghe, Yunnan Province and the curve characteristics are shown in Table 1. Figure 1 is the map of Midecun Tunnel.

\begin{tabular}{|c|c|c|c|}
\hline & & Left tunnel & Right tunnel \\
\hline $\begin{array}{c}\text { Boundary } \\
\text { mileage }\end{array}$ & & $\begin{array}{c}\text { ZK34+752.611 } \\
\text { ZK37+926.346 }\end{array}$ & $\mathrm{K} 34+781.034 \sim \mathrm{K} 36+424.870$ \\
\hline \multirow{2}{*}{$\begin{array}{l}\text { Curve } \\
\text { elements }\end{array}$} & $\mathrm{R}$ & 710 & 730 \\
\hline & $\mathrm{L}$ & 3173.735 & 1643.836 \\
\hline \multicolumn{2}{|l|}{$\begin{array}{l}\text { Boundary } \\
\text { mileage }\end{array}$} & $\begin{array}{c}\text { ZK37+926.346 } \\
\text { ZK38+569.533 }\end{array}$ & $\mathrm{K} 36+424.870 \sim \mathrm{K} 38+068.706$ \\
\hline \multirow{2}{*}{$\begin{array}{l}\text { Curve } \\
\text { elements }\end{array}$} & $\mathrm{R}$ & 710 & 730 \\
\hline & $\mathrm{L}$ & 643.187 & 1643.836 \\
\hline $\begin{array}{l}\text { Boundary } \\
\text { mileage }\end{array}$ & & $\begin{array}{c}\text { ZK38+569.533 } \\
\text { ZK39+770.859 }\end{array}$ & $\mathrm{K} 38+706.635 \sim \mathrm{K} 39+898.578$ \\
\hline \multirow{2}{*}{$\begin{array}{l}\text { Curve } \\
\text { elements }\end{array}$} & $\mathrm{R}$ & 750 & 750 \\
\hline & $\mathrm{L}$ & 1201.326 & 1191.943 \\
\hline
\end{tabular}

Table 2. Curve elements of the Midecun Spiral Tunnel.

\subsection{Physical model and boundary conditions}

Pipelines with different radius of curvature are constructed according to the calculation requirements.

Table 3. Detailed parameters of pipeline.

\begin{tabular}{ccc}
\hline & & \\
Length & $\mathrm{L} / \mathrm{m}$ & Pipe radius \\
$\mathrm{r} / \mathrm{m}$ & & Radius of pipe curvature \\
$\mathrm{R} / \mathrm{m}$
\end{tabular}




\begin{tabular}{|c|c|c|c|}
\hline S-1 & & & \\
\hline R-1 & & & 50 \\
\hline $\mathrm{R}-2$ & & & 100 \\
\hline $\mathrm{R}-3$ & & & 200 \\
\hline & $298.3 \mathrm{~m}$ & 1 & \\
\hline R-4 & & & 400 \\
\hline R-5 & & & 800 \\
\hline R-6 & & & 1200 \\
\hline R-7 & & & 1600 \\
\hline
\end{tabular}

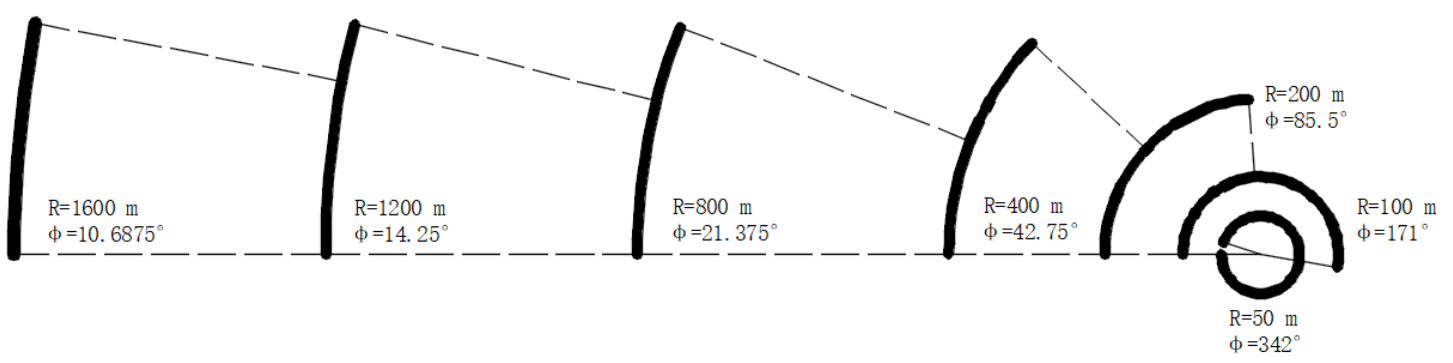

Fig.2. Different pipe corresponds to the radius and Angle

Detailed parameters of pipeline are shown in Table 2 . The pipes with different radius of curvature $\mathrm{R}$ have the same length $\mathrm{L}$ and the same radius $\mathrm{r}$. The variation trend of flow resistance in spiral pipe under different radius of curvature is studied. The pipes with different radius of curvature are shown in Figure 2. It can be seen from the diagram, along with the increase of radius of curvature, the same as the length of the pipe is more and more straight. The boundary condition of the pipe inlet is set as the pressure inlet, and the pressure is $0 \mathrm{~Pa}$; the pipe outlet is set as the velocity inlet, and the velocity is set as 1,3 and $10 \mathrm{~m} / \mathrm{s}$ respectively.

\section{Numerical Simulation Results}

\subsection{Flow field distribution in pipeline}

After the calculation, the wind speed distribution in the pipeline under different curvature radii was observed, as shown in Figure 3. Through observation, the maximum wind speed in the pipe was found and marked, as shown in Figure 3. It is obvious that as the radius of curvature increases, the position of the maximum velocity gradually moves towards the center of the pipe. When the radius of curvature is small, the maximum velocity is obviously close to the outside, while when the radius of curvature is larger, the maximum velocity is closer to the center.

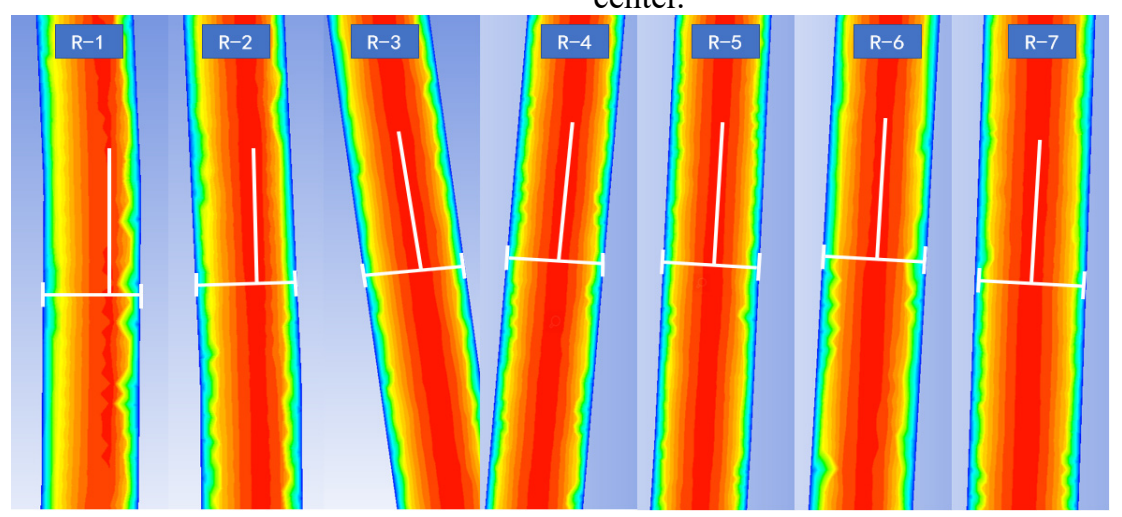

Fig. 3. Flow velocity distribution in pipe with different radius of curvature 


\subsection{Flow resistance study}

Two conditions are set in the calculation. The pipe inlet is the pressure inlet, and the outlet is the speed outlet, respectively setting 3 and $10 \mathrm{~m} / \mathrm{s}$. After the calculation is completed, the pressure value on the center line of the pipeline is derived and the pressure change curve is drawn in Figure 4.

The slope in the figure represents the change of resistance in the flow process. The same resistance coefficient is set in the pipeline during calculation, and there will be no local resistance in the pipeline with regular shape . Therefore, it can be considered that the slope in the figure represents the influence of the helix on the flow resistance. Therefore, it can be considered that the slope in the figure represents the influence of the helix on the flow resistance. It can be seen that the flow resistance changes at two different flow rates have similar trends. With the increase of the radius of curvature, the flow resistance of the same length spiral pipe is smaller.
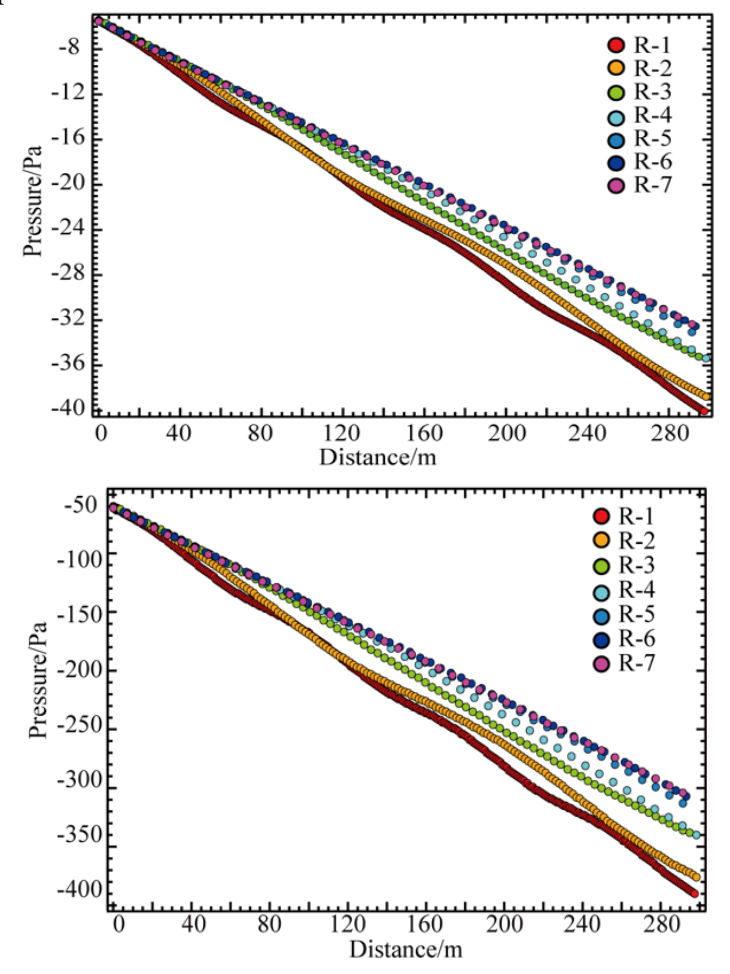

Fig.4. Curve of pressure in pipe with distance

\section{Conclusions}

In this paper, the flow resistance in spiral pipe is studied based on the village tunnel of Jian-ge-yuan expressway. It can be found from the calculation results that when the fluid flows in the spiral pipe, the flow velocity in the pipe is not distributed symmetrically like the linear pipe, but has an offset, and this offset gradually decreases with the increase of the spiral radius. It is found that no matter what the flow velocity is in the pipe, the change rate of flow resistance in the spiral pipe decreases with the increase of the spiral radius. This indicates that the spiral shape brings extra resistance to the flow, and the resistance decreases with the increase of the radius of curvature.

\section{References}

1. X.D. Huang, Z.M. Liu, S.L. Chen, J.K. Cui. Testing Methods and Application for Mine Ventilation Friction. Coal Mine Safety, 35, 13-15 (2004)

2. S.R. Cheng, J.J. Cheng. Measurement of mine ventilation resistance and analysis of several problems. Coal Mining, 72-74 (2006)

3. Y.H. Zeng, X.X. Ma. Study on the accuracy of ventilation resistance measured by the total differential pressure method. Coal Engineer, 5-6 (1998)

4. Shenyang Coal Mine Design and Research Institute. Friction resistance coefficient of mine ventilation roadway (A standard) table. (1985)

5. S. Li, X.F. Liu, J.X. Wang, Y.L. Zheng, S.M. Deng. Experimental reduced-scale study on the resistance characteristics of the ventilation system of a utility tunnel under different pipeline layouts. Tunnelling and Underground Space Technology, 90, 131-143 (2019)

6. I. Diego, S. Torno, J.Torano, M.Menendez, M. Gent. A practical use of CFD for ventilation of underground works. Tunnelling and Underground Space Technology, 26, 189-200 (2011)

7. W.L. Jin. Study on ventilation environment Parameters test of zhongnanshan Extra-Long Highway Tunnel in Qinling Mountains; Chang 'an university, (2006)

8. Y.H. Yu. Study on flow resistance and jet fan lift pressure in Jinping Tunnel; Southwest Jiaotong University, (2006)

9. Y.H. Yu, B. Lei, H.Q. Bi. Numerical simulation of flow field and local resistance in emergency stop zone of tunnel. Modern tunneling technology, 43, 49-52 (2006)

10. Chongqing Expressway Group, Southwest Jiaotong University. Longitudinal ventilation study of highway long tunnel; (1998)

11. Chongqing Expressway Group, Southwest Jiaotong University. Evaluation report on the effect of the Intelligent control system of Changchang Road Tunnel; (2006) 